\title{
Água um bem de todos: Interfaces desenvolvimento e sustentabilidade
}

\author{
How much Water an asset for all: Interfaces development and sustainability \\ El agua es un bien para todos: Las interfaces de desarrollo y sostenibilidad
}

Recebido: 30/06/2021 | Revisado: 06/07/2021 | Aceito: 09/07/2021 | Publicado: 19/07/2021

\author{
Simone Cesario Soares \\ ORCID: https://orcid.org/0000-0002-4219-5729 \\ Universidade Estadual do Oeste do Paraná, Brasil \\ E-mail: ccsimone@hotmail.com \\ Altevir Signor \\ ORCID: https://orcid.org/0000-0002-4659-6466 \\ Universidade Estadual do Oeste do Paraná, Brasil \\ E-mail:altevir.signor@gmail.com
}

\begin{abstract}
Resumo
A água é um bem necessário a todos os seres vivos, reconhecida pela ONU como um direito fundamental. Desta forma as políticas públicas tem papel essencial, tanto para garantir o fornecimento quanto à preservação. Assim este trabalho buscou compreender e analisar os vários fatores que contribuem para que a água potável chegue à população. Para sua realização foram utilizados dados de fontes bibliográficas, como artigos científicos, discussões acerca da temática, dados de órgãos de pesquisa como: IBGE, ANA, INPE dentre outros. Percebeu-se a falta estruturas de saneamento básico em muitas regiões do país, falta de consciência da população quanto ao uso responsável. Consideramos também que a produção agrícola e industrial contribui para a contaminação da água através de descarte de dejetos, agrotóxicos, ou ainda produtos químicos que contaminam o solo, rios e nascentes. Ao mesmo tempo em que as ações antrópicas tais como queimadas e desmatamentos tem grande relevância nas condições ambientais e tem historicamente contribuído com estiagens. O estudo indicou ainda que a busca pela sustentabilidade passa pela conservação ambiental dos recursos hídricos, que apesar das políticas públicas trazerem em seus documentos leis e orientações acerca de sua utilização bem como de sua preservação, ainda estamos longe garantir este bem as gerações futuras, pois o auge do alcance desses objetivos passa pela conscientização populacional. Condições que permitirá mitigar os impactos ao meio-ambiente, buscando alternativas sustentáveis, um caminho importante a ser considerado é a educação ambiental que não ocorre apenas na escola e sim por toda a sociedade.
\end{abstract}

Palavras-chave: Água; Sustentabilidade; Desenvolvimento; Direitos humanos; Produção.

\begin{abstract}
Water is a necessary asset for all living beings, recognised by the UN as a fundamental right. Thus, public policies play an essential role, both to ensure supply and preservation. Thus, this work sought to understand and analyze the various factors that contribute to drinking water reaching the population. To carry it out, data from bibliographic sources were used, such as scientific articles, discussions on the theme, data from research bodies such as: IBGE, ANA, INPE among others. We noticed the lack of basic sanitation structures in many regions of the country and the population's lack of awareness about the responsible use of water. We also consider that agricultural and industrial production contributes to the contamination of water through the disposal of waste, pesticides or even chemicals that contaminate the soil, rivers and springs. At the same time anthropic actions such as burning and deforestation have great relevance in environmental conditions and have historically contributed to droughts. The study also indicated that the search for sustainability goes through the environmental conservation of water resources, which despite public policies bringing in their documents laws and guidelines about their use as well as their preservation, we are still far from guaranteeing this asset to future generations, because the culmination of the achievement of these goals goes through the awareness of the population. Conditions that will mitigate the impacts on the environment, seeking sustainable alternatives, an important path to be considered is environmental education that does not occur only in school but throughout society.
\end{abstract}

Keywords: Water; Sustainability; Environment; Human rights; Production.

\section{Resumen}

El agua es un bien necesario para todos los seres vivos, reconocido por la ONU como un derecho fundamental. Por ello, las políticas públicas tienen un papel esencial, tanto para garantizar la oferta como la conservación. Por ello, este estudio pretendía comprender y analizar los diversos factores que contribuyen a que el agua potable llegue a la población. Para su realización, se utilizaron datos de fuentes bibliográficas, como artículos científicos, discusiones sobre el tema, datos de organismos de investigación como: IBGE, ANA, INPE entre otros. Se constató la falta de estructuras de saneamiento básico en muchas regiones del país, la falta de concienciación de la población respecto al 
uso responsable. También consideramos que la producción agrícola e industrial contribuye a la contaminación del agua mediante el vertido de residuos, pesticidas o incluso productos químicos que contaminan el suelo, los ríos y los manantiales. Al mismo tiempo, acciones antrópicas como las quemas y la deforestación tienen gran relevancia en las condiciones ambientales y han contribuido históricamente a las sequías. El estudio también indicó que la búsqueda de la sustentabilidad pasa por la conservación ambiental de los recursos hídricos, que a pesar de que las políticas públicas traen en sus documentos leyes y lineamientos sobre su uso así como su preservación, aún estamos lejos de asegurar este bien a las futuras generaciones, pues la culminación del logro de estas metas pasa por la concientización de la población. Condiciones que mitigarán los impactos al medio ambiente, buscando alternativas sostenibles, un camino importante a considerar es la educación ambiental que no se da sólo en la escuela sino en toda la sociedad.

Palabras clave: Agua; Sostenibilidad; Medio ambiente; Derechos humanos; Producción.

\section{Introdução}

Para que a sociedade tenha condições de se desenvolver é a disponibilidade de água potável. No entanto a busca pela alta produtividade considerando as demandas contemporâneas, seja, pelo alimento ou outros bens de consumo, a partir de um processo altamente produtivo que por vezes desconsidera os danos ambientais causados, danos este que podem ser irreversíveis. Um dos fatores que contribuem para este cenário é alta densidade demográfica de algumas regiões do país. Espaços geográficos formados por médias e grandes cidades formando as megalópoles.

Com a escassez de recursos hídricos, contaminações de lençóis freáticos, redução da pluviosidade com consequente redução dos volumes de águas nos rios e aumento da poluição advinda de seu uso inadequado ou inconsciente. Sendo assim, como podemos esperar que haja condições ambientais adequadas as futuras gerações? Na contemporaneidade temos vivenciando problemáticas ambientais desconectadas de políticas públicas efetivas e da falta de conjuntura dessas políticas com o setor produtivo a fim de garantir a disponibilidade desses recursos naturais em quantidade e qualidade para as futuras gerações.

O presente estudo avaliou as informações existentes a respeito das condições produtivas e suas consequências, principalmente relacionadas aos aspectos da necessidade de equilíbrio entre a conservação ambiental e o processo produtivo, tendo em vista o desenvolvimento sustentável. Desta forma foram consultados artigos científicos, base de dados de órgãos governamentais e de plataformas digitais disponíveis.

\section{Metodologia}

O trabalho foi realizado a partir da utilização de dados de fontes bibliográficas, como artigos científicos, discussões acerca da temática, dados de órgãos de pesquisa como: IBGE, ANA, INPE, SNIS dentre outros órgãos de pesquisas governamentais. Buscando compreender os impasses enfrentados pelo país para oferecer água de qualidade à população atual bem como seu planejamento de preservação para as futuras gerações. O estudo é quali-quantitativo pois mescla as observações qualitativas ao estruturar as observações e discussões sobre a temática e quantitativo ao abordar os números e seus indicativos a respeito da temática. Podemos citar como material referencial na metodologia adotada Volpato (2007; 2019), Koche (2011) e Pereira et al. (2018). A estruturação do artigo baseou-se em dados divulgados pelos órgãos públicos e de revisões bibliográficas disponíveis em publicações em revistas científicas da área.

\section{Resultados e Discussão}

\section{1 Água um bem comum de todos}

A água é um bem de todos os seres vivos, humanos, animais e plantas. Ao mesmo tempo devemos considerar que ela não está presente em todos os locais, nem em qualidade e quantidade suficiente para o consumo dos diferentes grupos. Assim como, é um bem limitado e inalienável. 
A Organização das Nações Unidas (ONU) aponta que o século vinte e um vem sendo marcado por desastres climáticos, o que torna as pessoas em vulnerabilidade social, numa condição ainda mais critica, ao considerar a falta de água, pelas secas severas, a falta de saneamento básico ou pelos desastres ambientais provocados por ações antrópicas. Segundo dados da ONU (2019) houve cerca de 7.348 desastres ecológicos no mundo nas últimas duas décadas. Aproximadamente 1,23 milhões de pessoas morreram, cerca de 60 mil por ano, além disso, cerca de 4 bilhões de pessoas foram afetadas pelos desastres ambientais. As inundações foram responsáveis por mais de 40 dos desastres, afetando cerca de 1,65 milhões de pessoas no mundo, além das tempestades, terremotos e temperaturas extremas, conforme aponta o relatório (ONU, 2017).

O país evoluiu pouco ou nada no quesito de cooperação em ações envolvendo os órgãos municipais com as autarquias estaduais com a finalidade de consórcios públicos para solução de problemas. Nesse sentido as ações que buscam o conjunto de ações para soluções de problemas que envolvem o meio ambiente (25\%), desenvolvimento urbano (20,55\%), saneamento básico (19,15\%), turismo (13,15\%), assistência e desenvolvimento social (12,7\%), gestão das águas (11,3\%), educação (10,75\%), cultura $(9,85 \%)$, transporte $(9,15 \%)$ e habitação $(7,6 \%)$ (IBGE, 2019) estão desconexas da realidade, condições que demonstra a falta de políticas direcionadas a solução conjunta dos problemas que mais assolam o país. Espera-se por parte dos gestores municipais, estaduais e federais união conjunta nas ações para a solução dos problemas, mas não é o que se observa quando se analisa as ações efetivas nesse sentido, como pode ser observado nos dados acima, condições preocupantes para uma nação que busca ascensão em níveis de desenvolvimento de forma sustentável (IBGE, 2019).

Segundo dados do IBGE (2017) dos 5.570 municípios brasileiros, 5.444 (99,53\%) disponibilizam serviços de abastecimento de água por rede geral de distribuição, embora uma parcela significativa disso não seja tratada. Entretanto, apenas 2126 têm políticas de saneamento básico, ou seja, 38,17\% dos municípios brasileiros disponibilizam ações voltadas ao saneamento básico, desses apenas 1804 municípios tem instrumentos legais, sejam em leis, decretos ou portarias regulamentadoras de ações para o saneamento básico, o que representa apenas 32,39\% dos municípios brasileiros (IBGE, 2017). Condições que são no mínimo assustadoras, pois esse é o princípio básico para que a população tenha boas condições de vida e saúde e a água que a elas chega tenha garantias mínimas de consumo. Esse número é ainda mais alarmante, quando se avalia os parâmetros para a garantia do atendimento essencial a saúde pública, no qual apenas 695 municípios (12,48\%) tem ações legais que contemplam esses parâmetros (IBGE, 2017). Isso indica um completo abandono dos órgãos gestores sejam eles municipais estaduais ou da federação com políticas, leis ou normatizações que se voltem ao atendimento daquilo que é a essência do desenvolvimento de qualquer nação, o atendimento as condições básicas de saúde pública, de saneamento, de bem estar para que o país possa explorar o seu potencial de desenvolvimento estruturados em condições que permitam a sociedade o seu amplo desenvolvimento cidadão. Vale ressaltar que existiam 1342 municípios (24\%) que destacavam estarem elaborando suas políticas de saneamento básico, como sabemos entre a elaboração e a implantação leva-se alguns anos, condições preocupantes para um país que deseja alavancar estágios de desenvolvimento e estruturação de políticas públicas que se mostram pouco atuantes, fracamente eficientes e altamente frágeis.

Levantamento realizado pelo Instituto Trata Brasil em 2018, revela que cerca de (47\%) do Brasil continua sem acesso a sistemas de esgoto sanitário, corresponde a quase 100 milhões de pessoas. Os dados revelaram que mais de $16 \%$ da população, ou seja, cerca de 35 milhões de pessoas, não têm acesso à água tratada (SNIS, 2020).

A ONU na Declaração sobre o Direito ao Desenvolvimento de 1984 reconhece no artigo $2^{\circ}$ que:

§1. A pessoa humana é o sujeito central do desenvolvimento e deveria ser participante ativo e beneficiário do direito ao desenvolvimento;

$\S 2$. Todos os seres humanos têm responsabilidade pelo desenvolvimento, individual e coletivamente, levando-se em conta a necessidade de pleno respeito aos seus direitos humanos e liberdades fundamentais, bem como seus deveres para com a comunidade, que sozinhos podem assegurar a realização livre e completa do ser humano e deveriam por isso promover e proteger uma ordem política, social e econômica apropriada para o desenvolvimento. 
Muitas populações vivem em situação de vulnerabilidade, onde a falta de água potável os torna ainda mais vulneráveis diante da miséria. Leonardo Boff (2015) afirma que a sustentabilidade de uma sociedade pode ser medida pela capacidade de inclusão, em suas palavras: "A sustentabilidade de uma sociedade se mede por sua capacidade de incluir a todos e garantir-lhes os meios de uma vida suficiente e decente" (BOFF, 2015, p. 20).

Na ECO-92 encontro promovido tratar das questões ambientais, a água já era um tema em pauta, do encontro originou-se a Agenda 21, a qual afirma, em seu Capítulo 18, que:

"A água é necessária em todos os aspectos da vida. O objetivo geral é assegurar que se mantenha uma oferta adequada de água de boa qualidade para toda a população do planeta, ao mesmo tempo em que se preserve as funções hidrológicas, biológicas e químicas dos ecossistemas, adaptando as atividades humanas aos limites da capacidade da natureza e combatendo vetores de moléstias relacionadas com a água. Tecnologias inovadoras, inclusive o aperfeiçoamento de tecnologias nativas, são necessárias para aproveitar plenamente os recursos hídricos limitados e protegê-los da poluição" (ONU, 1992).

\subsection{As Políticas Públicas para a conservação e distribuição da água no Brasil}

Apesar de o Brasil ter disponível em seu território grande quantidade de água doce, ela não está distribuída de maneira uniforme, assim como a distribuição populacional não segue de maneira uniforme a distribuição dos recursos hídricos. A concentração populacional e dos recursos hídricos no Brasil esta distribuído da seguinte forma: região Norte do país detém o maior volume de recursos hídricos com 68,5\% e é a quarta região em concentração populacional (17.082.160 pessoas), a região Centro Oeste detém 15,7\% do volume hídrico e apresenta a menor concentração populacional (10.102.113 pessoas), a região Sul apresenta 6,5\% dos recursos hídricos e tem a terceira concentração populacional (30.192.315 pessoas), a região Sudeste apresenta $6 \%$ dos recursos hídricos e detém a maior concentração populacional (88.985.106 pessoas) e a região Nordeste apresenta apenas 3,3\% dos recursos hídricos e é a segunda maior concentração populacional (47.757.622 pessoas) do país (IBGE, 2020; ANA, 2020).

No Brasil a lei 94.33/1997 (BRASIL, 1997) instituiu a Política Nacional de Recursos Hídricos, criando o Sistema Nacional de Gerenciamento de Recursos Hídricos, regulamentada pelo inciso XIX do art. 21 da Constituição Federal, que alterada pelo art. $1^{\circ}$ da Lei $\mathrm{n}^{\circ}$ 8.001, de 13 de março de 1990, modificou a Lei $\mathrm{n}^{\circ}$ 7.990, de 28 de dezembro de 1989, em seu artigo $1^{\circ}$; inciso I esclarece que a água é um bem de domínio público, ou seja, além de ser um bem comum de todos, é função do setor público sua administração, conservação, bem como a educação para a manutenção deste as futuras gerações (BRASIL, 1997).

Nesta perspectiva o estado tem a função de assegurar às futuras gerações o acesso à água de qualidade, ao mesmo tempo em que reconhece o caráter limitado deste recurso, conforme Cap. $2^{\circ}$ CAPÍTULO II abaixo:

Art. $2^{\circ}$ São objetivos da Política Nacional de Recursos Hídricos:

I - assegurar à atual e às futuras gerações a necessária disponibilidade de água, em padrões de qualidade adequados aos respectivos usos;

II - a utilização racional e integrada dos recursos hídricos, incluindo o transporte aquaviário, com vistas ao desenvolvimento sustentável;

III - a prevenção e a defesa contra eventos hidrológicos críticos de origem natural ou decorrentes do uso inadequado dos recursos naturais;

IV - incentivar e promover a captação, a preservação e o aproveitamento de águas pluviais.

Nesta perspectiva cabe ao estado mediar o processo de desenvolvimento econômico, ou seja, as atividades produtivas com a manutenção e/ou conservação do meio ambiente. Desta forma a União em comum acordo com os estados, articulada e gerencia os recursos hídricos do país. Conforme Lei n 94.33/1997 Cap. 3, Art. $3^{\circ}$ : - II - a adequação da gestão de recursos hídricos às apresenta de forma clara a preocupação para com a sustentabilidade deste recurso natural e limitado. Outro fator importante acerca dos recursos hídricos é o desperdício deste bem. A ONU recomenda que cada pessoa faça uso de até 110 
litros de água por dia, isso seria suficiente para atender as necessidades básicas de higiene e alimentação. No Brasil, por exemplo, segundo a ONU consumimos cerca de 154 litros de água em média por habitante por dia (ONU, 2018).

Ao mesmo tempo, além de elementos como, por exemplo, a escassez de chuvas, contaminação dos corpos d'água ainda temos o desperdício gerado pelos administradores destes recursos, que no Brasil, pode se tratar de empresas privadas ou públicas e com a falta ou inadequados processos de saneamento além do baixíssimo índice de esgoto funcional acarreta em aumento do processo poluidor. Segundo levantamento de dados do Sistema Nacional de Informações sobre Saneamento (SNIS) de 2018, o Brasil desperdiça 38,5\% da água tratada pelas prestadoras de serviço, condições que para o momento em que vivemos e com as tecnologias disponíveis é inaceitável.

Outro fator que contribui significativamente para a degradação ambiental no Brasil, certamente é o desmatamento. Segundo dados publicados pelo Instituto Nacional de Pesquisas Espaciais (INPE), no período de agosto (2019) a julho de 2020, foram registrados cerca de $7340 \mathrm{Km}^{2}$ de desmatamento do bioma Cerrado, o que corresponde a um aumento no desmatamento de $13 \%$ em relação ao ano anterior (INPE, 2020). Além disso, sucessivas queimadas acidentais e/ou criminosas tem sobremaneira acarretado maiores problemas de saúde pública. Por consequência, temos observado redução significativa dos volumes pluviométricos em várias regiões do país que podem estar diretamente relacionados aos frequentes e intensificados processos de desmatamentos e, as grandes áreas improdutivas (morros, solos inférteis, áreas contaminadas, etc.;) provocadas por ações antrópicas ou pelo mal uso no processo produtivo tem reduzido significativamente o volume de florestas e matas, que podem ter comprometido ainda mais as baixas precipitações observadas na região.

A promoção desse desmatamento comumente está ligada a produção agrícola e agropecuária que por vezes ocorre de maneira desenfreada ou pela falta de um planejamento dos processos produtivos, que sem planejamento adequado e sem uma ação efetiva e organizada do estado. Promovendo queimadas e buscando por este meio para invadir áreas de preservação e expandindo sua produção com finalidades em geral econômicas desconsiderando aspectos sociais e ambientais. Assim Rossoni (2020), afirma que: "A dificuldade em enfrentar o desmatamento está associada à complexidade de sua dinâmica. Além da ocupação territorial, fatores como os subsídios fiscais, a atividade agropecuária e o valor das terras são comumente citados como fatores relacionados ao desmatamento" (Rossoni, et al., 2020, p.113).

Percebe-se que as áreas de queimadas aumentaram significativamente em todos os biomas brasileiros na última década. Sendo mais evidente no bioma Amazônia que tem sido mais atingido em área total de queimadas nos seguintes anos: 2003, 2004, 2005, 2007, 2013, 2016, 2018, 2019 e 2020, tendo seus picos de área queimada em km² nos anos de 2016 e 2019 (Tabela 1) (INPE, 2020). Pode-se observar que as queimadas tem sido um dos grandes problemas a serem solucionados pelas políticas públicas, principalmente pelo fato de que a queima não somente causa problemas de saúde pública em muitas regiões do país vinculadas a propagação de gases e fumaças, mas principalmente pelo fato de que com as queimadas perdem-se riquezas incalculáveis, seja pelo valor biológico das áreas desmatadas e queimadas, perdas genéticas, extinção de espécies nativas, problemas diretamente relacionadas aos mananciais aquáticos e extinção de nascentes, assim como o grande prejuízo nacional de matéria prima que são as madeiras que por se perderem nas queimadas geram prejuízos incalculáveis ao país. Além de biomas que abrigam animais e plantas especificas ou originárias ao longo do tempo, em persistindo às queimadas de forma irresponsável podem ter sua população reduzida ou mesmo extinta, além da importância bioma ser descaracterizado com o passar dos anos. 
Tabela 1: Representação das áreas de queimadas nos biomas brasileiros ao longo da última década. Dados compilados do INPE.

\begin{tabular}{|l|c|c|c|c|c|c|c|}
\hline Ano & Amazônia & Caatinga & Cerrado & Mata Atlântica & Pampa & Pantanal & Total Anual \\
\hline 2003 & 9.962 & 2782 & 1951 & 1250 & 18 & 296 & 16259 \\
\hline 2004 & 6.431 & 591 & 1926 & 777 & 359 & 633 & 10717 \\
\hline 2005 & 5.065 & 11771 & 2571 & 1765 & 427 & 414 & 12013 \\
\hline 2006 & 3.490 & 1061 & 1688 & 1302 & 217 & 66 & 7824 \\
\hline 2007 & 8.166 & 1202 & 2770 & 1037 & 27 & 125 & 13327 \\
\hline 2008 & 3.567 & 596 & 1078 & 753 & 187 & 79 & 6260 \\
\hline 2009 & 2.680 & 1023 & 1306 & 1930 & 355 & 1667 & 8961 \\
\hline 2010 & 3.955 & 506 & 3353 & 1089 & 128 & 428 & 9459 \\
\hline 2011 & 1.577 & 100 & 1243 & 344 & 65 & 90 & 3419 \\
\hline 2012 & 3.386 & 2012 & 2719 & 989 & 156 & 592 & 9854 \\
\hline 2013 & 5.028 & 829 & 1616 & 836 & 136 & 484 & 8929 \\
\hline 2014 & 4.679 & 397 & 1721 & 468 & 62 & 239 & 7566 \\
\hline 2015 & 4.501 & 1148 & 2002 & 864 & 174 & 244 & 8933 \\
\hline 2016 & 10.946 & 564 & 4113 & 1620 & 46 & 101 & 17390 \\
\hline 2017 & 1.399 & 652 & 2082 & 535 & 47 & 560 & 5275 \\
\hline 2018 & 5.398 & 732 & 1462 & 716 & 146 & 40 & 8494 \\
\hline 2019 & 11.773 & 196 & 2036 & 1031 & 106 & 1298 & 16440 \\
\hline 2020 & 7.505 & 548 & 3541 & 3859 & 4669 & 3686 & 23808 \\
\hline$* 2021$ & 1378 & 1559 & 2389 & 1079 & 201 & 243 & 6.849 \\
\hline
\end{tabular}

*Dados referente ao período de janeiro a abril de 2021.

Fonte: Dados obtidos do Instituto Nacional de Pesquisas espaciais - INPE. https:/queimadas.dgi.inpe.br/queimadas/aq1km/

A intensa redução das precipitações dos últimos anos em diversas regiões do país levou o Sistema Nacional de Meteorologia (SNM) a publicar em maio de 2021, uma nota em conjunto com o Instituto Nacional de Meteorologia (INMET), Instituto Nacional de Pesquisas Espaciais (INPE) e Centro Gestor e Operacional do Sistema de Proteção da Amazônia (CENSIPAM), com a participação de todos os órgãos federais ligados à meteorologia, e com a Agência Nacional de Águas e Saneamento Básico (ANA) e o Centro Nacional de Monitoramento e Alerta de Desastres Naturais alertando para a baixa incidência de chuva em várias regiões do país, regiões estas que tem grande densidade populacional. Trata-se de um documento importante, é um Alerta de Emergência Hídrica associada à escassez de precipitação para a região hidrográfica da Bacia do Paraná abrangendo os estados de Minas Gerais, Goiás, Mato Grosso do Sul, São Paulo e Paraná para o período de Junho a Setembro de 2021.

O Alerta apresenta informações sobre as perspectivas climáticas para os anos de 2021/2022 o qual indica que a maior parte da região central do país, a partir de maio até final de setembro, entra num período com menor volume de chuvas, ou seja, a estação seca. Mas isso é algo limitado e bastante frágil, embora importante a alerta, pelos históricos observados e as condições pluviométricas disponíveis ao longo do tempo, esses órgãos falham em aprofundar as possíveis consequências e em assumir seus papéis com a responsabilidade que lhe cabem e que precisam ser de fato encaradas.

Os dados indicados pelo Alerta demonstram através do índice de precipitação (SPI) que a situação atual de déficit de precipitação é severa, ou seja, na maior parte da bacia do Rio Paraná a situação apresenta-se de moderado a extremo, quando considerada a precipitação mensal observada e prevista na bacia do Rio Paraná, entre Outubro/2019 e Abril/2021 (SNM/maio, 2021). Potencializando assim o risco de desabastecimento de água bem como energético.

\subsection{Atividades Produtivas: os grandes contaminantes das águas}

Toda e qualquer nação que busca seu desenvolvimento como forma de estruturação em sociedade deve considerar a sustentabilidade como único meio para concretizar tal objetivo. Nesta perspectiva deve-se considerar as necessidades do presente sem o comprometimento dos recursos naturais as gerações futuras, ou seja, é necessário que esse desenvolvimento seja economicamente eficiente, socialmente equitativo e ecologicamente tolerável. 
Comumente, ao tratarmos da sustentabilidade consideramos que estamos tratando de nós enquanto seres humanos, e nos dissociamos dos demais seres que vivem neste planeta. Boff aponta que "formamos uma única entidade" (Boff, p. 2015). Ou seja, o próprio homem se colocou como centro de tudo, esquecendo-se que ele próprio precisa da natureza, seja ela animal ou vegetal.

O processo de exploração, degradação bem como a poluição dos recursos hídricos tem alcança efeitos alarmantes, efeitos estes que podem afetar a oferta de água a uma parcela significativa da sociedade. Assim como, comprometer a produção de alimentos, a diversidade da fauna e da flora e agravar a condição dos mais vulneráveis.

O problema ambiental visualizado atualmente, a partir de uma crise, aparece no problema do lixo, da poluição das águas, do empobrecimento do solo, nas queimas de nossas florestas, dos desmatamentos, através do aquecimento global, promovidas por ações antrópicas a partir do movimento de produzir e consumir a partir do sistema poderá levar a sociedade a consequências irreversíveis (Schons, 2012).

Leonardo Boff (2015) aponta que nossa condição ambiental é tão degradante que a continuidade deste processo não nos possibilitará salvar a própria espécie humana. Essa degradação ecológica é fruto de nosso modo de vida, no qual produzimos e consumimos, sem refletir sobre os danos causados ou mesmo no futuro desta e das próximas gerações.

Netto e Braz corroboram:

“A sociedade não pode existir sem a natureza - afinal, é a natureza, transformada pelo trabalho, que propicia as condições da manutenção da vida dos membros da sociedade. Toda e qualquer sociedade humana tem sua existência hipotecada à existência da natureza - o que varia historicamente é a modalidade da relação da sociedade com a natureza: variam ao longo da história, os tipos de transformação que, através do trabalho, a sociedade opera nos elementos naturais para deles se servir, bem como os meios empregados nessa transformação" (Netto; Braz, 2008, p. $35)$.

Dupas (2007) afirma que sendo a globalização um processo acelerado, no qual se busca o lucro a qualquer preço, também provoca exclusão. Como afirma Dupas: "A globalização não amplia os espaços, estreita-os; não assume responsabilidades sociais e ambientais; pelo contrário, acumula problemas, transforma-se em sintomas de sobrecarga" (Dupas, 2007, p. 78) que constantemente precisam ser estudados, analisados, refletidos, adequados, estruturados e replanejados para atendimento das demandas e de suas necessidades na busca em oferecer a dignidade humana e de desenvolvimento social.

A busca pelo desenvolvimento econômico não pode se dar a qualquer custo, pois o preço a ser pago pela sociedade pode ser imensurável, haja vistas a finitude da natureza e aos problemas sociais gerados. O fator econômico é importante, mas não deve ser o único elemento a ser considerado. A utilização demasiada da natureza pode levar a escassez da própria água, em quantidade ou qualidade para a produção agroindustrial, mas essencialmente necessária a própria sobrevivência humana.

A expansão das cidades nas últimas décadas tem sido responsável pelo aumento das atividades antrópicas considerando o uso dos recursos naturais, uma vez que elas concentram grande parte da população. Concentrando as atividades produtivas sejam elas de cunho industrial, comercial, demandam grandes construções e reduzem ou eliminam infiltrações de água no solo e subsolo que tem levado a reduções significativas de nascentes, muitas foram ou estão sendo eliminadas, resultando em enchentes, redução dos níveis de água nos rios que cercam estas cidades, além do baixo índice de tratamento do esgoto que elevam poluições aos rios e também aos lençóis freáticos. No entanto, são necessárias ao desenvolvimento da sociedade e do país, tendo em vista a concentração da população em determinadas regiões, condição que emergencialmente demandam políticas públicas de planejamento estrutural, atendendo as necessidades de saneamento básico, escoamento do excesso de chuvas, urbanização, tratamento de resíduos industriais, de abastecimento com água potável, áreas de reflorestamento urbano, parques ecológicos e de controle de agrotóxicos. 
Muitos são os fatores que interferem na qualidade de vida da sociedade essencialmente nas cidades, o acesso a água potável. De maneira geral, a poluição dos corpos d'água é causada pela introdução de matéria alterando as características da água e podendo afetar a biota, através do descarte de produtos químicos das indústrias, esgotos gerados, bem como resíduos da construção civil. Nagalli, aponta que um dos problemas enfrentados é a falta de saneamento básico, bem como produtos descartados de forma incorreta, levando a contaminação dos corpos d'água, conforme cita: "Assim podemos considerar que a maior parte dos contaminantes são de origem química presentes em águas superficiais e subterrâneas e estão relacionada às fontes industriais, agrícolas e de esgotos domésticos (Nagalli, et al., 2009, p. 02).

A contribuição dos poluentes lançados clandestinamente pelas comunidades interfere negativamente na qualidade da água dos córregos. Segundo Alier: "À medida que se expande a escala da economia, mais resíduos são gerados, mais os sistemas naturais são comprometidos, mais se deterioram os direitos das gerações futuras, mais o conhecimento dos recursos genéticos são perdidos" (Alier, 2014, p. 33-36).

Os agrotóxicos são outra fonte contaminante. Segundo o Ministério da Saúde agrotóxicos podem ser definidos como:

"Agrotóxicos são produtos químicos sintéticos usados para matar insetos, larvas, fungos, carrapatos sob a justificativa de controlar as doenças provocadas por esses vetores e de regular o crescimento da vegetação, tanto no ambiente rural quanto urbano. Os agrotóxicos tem seu uso tanto em atividades agrícolas como não agrícolas. As agrícolas são relacionadas ao setor de produção, seja na limpeza do terreno e preparação do solo, na etapa de acompanhamento da lavoura, no deposito e no beneficiamento de produtos agrícolas, nas pastagens e nas florestas plantadas. $\mathrm{O}$ uso não agrícola é feito em florestas nativas ou outros ecossistemas, como lagos e açudes, por exemplo" (BRASIL, 2019).

O Brasil é um dos grandes consumidores mundiais de agrotóxicos e, que apesar da existência de leis bem como de orientações quanto à comercialização e uso, os riscos da exposição humana a esses contaminantes ainda são uma realidade. E por consequência as populações que habitam próximo às áreas cultivadas com agrotóxicos podem consumir água ou alimentos contaminados, bem como inalar as substâncias que eventualmente estejam no ar de forma direta.

Segundo Nege (2016), a população da região Oeste do Paraná apresenta altos índices de câncer onde comumente se desenvolvem atividades agrícolas relacionadas ao intenso uso de agrotóxicos. Esta região tem uma alta produtividade de soja, principalmente nas cidades de Toledo e Cascavel e com isso têm altos índices do uso de agrotóxicos, que segundo Carneiro (2012), esta é a atividade agrícola que mais utiliza agrotóxicos no país.

A região oeste do Paraná produz cerca de $25 \%$ do pescado produzido do Brasil, no entanto, a caracterização dos efluentes (resíduos gerados pelo peixes) produzida pela atividade de piscicultura em tanques escavados no solo apontou para a necessidade da aplicação de boas práticas de manejo durante o cultivo, a fim de evitar níveis elevados de concentração de nutrientes liberados no meio ambiente durante o processo de despesca. Sendo identificada a degradação progressiva da qualidade de água e aumento de matéria orgânica do efluente durante o processo de despesca, cujo efluente são lançado aos rios (Coldebella, et al., 2018) com alta capacidade poluente ameaçando o meio ambiente e a qualidade de água. Como essa é uma atividade econômica que tem se expandido significativamente na região e no país na última década merece atenção dos órgãos públicos e uma política direcionada aos sistemas de produção de forma a mitigar o impacto ambiental dessa atividade e promover o desenvolvimento social, tendo em vista o equilíbrio entre economia e meio ambiente.

Apesar de no Brasil haverem leis e orientações acerca da preservação ambiental, muitas das ações são falhas ou ineficazes. Ainda persiste em muitas regiões do país a falta de estruturas de saneamento básico, como por exemplo a falta de tratamento de esgotos, a falta de água potável que não chega na torneira de uma parte expressiva da população brasileira, a própria falta de consciência da população quanto ao uso consciente ou responsável. Consideremos também que a produção agrícola e industrial contribui para a contaminação da água através de descarte de dejetos, agrotóxicos, ou ainda produtos 
químicos que contaminam o solo, rios e nascentes. Ao mesmo tempo em que as ações antrópicas tais como queimadas e desmatamento tem grande relevância nas condições ambientais.

O estudo indicou ainda que a busca pela sustentabilidade passa pelo aspecto hídrico, e que apesar das políticas públicas trazerem em seus documentos leis e orientações acerca de sua utilização bem como de sua preservação, ainda estamos longe garantir este bem as gerações futuras. Os processos produtivos precisam considerar a conservação desses ambientes, pois deles dependem suas constantes produções, manutenção de suas riquezas e a sustentabilidade as futuras gerações. Condições que permitirá mitigar os impactos ao meio-ambiente, buscando alternativas sustentáveis, um caminho importante a ser considerado é a educação ambiental que não ocorre apenas na escola e sim por toda a sociedade em todos os seus níveis.

\section{Considerações Finais}

Com o trabalho pode-se observar que estamos distantes de um processo real de equilibrar o desenvolvimento econômico com a manutenção ou conservação do meio ambiente, bem estar e de saúde da população, condições estas que são essenciais ao desenvolvimento sustentável.

Muitas conquistas têm sido alcançadas com aspectos legais e constituídas para atendimento ao que entendemos como sendo essencial para obtenção de ações voltadas a melhorias dos processos produtivos que levem em consideração o valor agregado às consequências ambientais causadas pelas ações produtivas e não somente os resultados econômicos daquela ação. Entretanto, inúmeros são os desafios de se fazer valer tais incorporações ao processo produtivo, uma vez que é crescente a demanda de alimentos e do processo produtivo cada vez mais alienado aos resultados econômicos.

Dentro das atuais perspectivas, tornam-se fundamentais ações políticas efetivas no sentido de minimizar os impactos gerados pelo processo produtivo ao meio ambiente e o desenvolvimento de tecnologias através dessas políticas públicas que tornam possíveis um equilíbrio que de fato nos conduzam ao desenvolvimento sustentável.

Assim percebe-se a necessidade de elaboração de políticas públicas, ambientais e econômicas, mais eficazes ações conjuntas entre os órgãos gestores municipais, estaduais e federais no controle de um saneamento básico eficiente e que atenda aos brasileiros de forma íntegra, melhoria da qualidade de saúde pública, formas de utilização responsável dos recursos hídricos, com o intuito de promover uso racional de nossas riquezas, evitando a contaminação dos nossos recursos ambientais, bem como a redução dos desperdícios de água no processo produtivo de cadeias do agronegócio e da indústria.

Investigações futuras devem focar na efetividade das políticas públicas e se estas consideram de fato as informações disponíveis nos órgãos públicos e privados que disponibilizam tais informações, nos impactos a sociedade que as ações antrópicas efetivadas trazem e as consequências que isso poderá gerar as futuras gerações, aliado a isso indicativos de ações mitigadoras e solução dos problemas hora abordados, além de outros que possivelmente surgirão e que sirvam de planejamento para futuras políticas públicas direcionadas a solução de problemas e que venham a servir de base para o desenvolvimento sustentável.

\section{Referências}

ANA (2017). Agência Nacional de Águas. Água na Indústria: Uso e coeficientes técnicos. http://www3.snirh.gov.br/portal/snirh/centrais-de-conteudos/conjuntura-dos-recursoshidricos.

ANA (2017). Agência Nacional de Águas. Conjuntura dos Recursos Hídricos no Brasil. http://www3.snirh.gov.br/portal/snirh/centrais-de-conteudos/conjuntura-dos-recursoshidricos.

ANA (2005). Agência Nacional de Águas. Disponibilidade e demandas de recursos hídricos no Brasil. In: ANA. Cadernos de Recursos Hídricos. Volume 2. Brasília: ANA.

Alier, J. M. (2007). O ecologismo dos pobres. São Paulo: Contexto. 379p.

Amorin, J. A. A. (2015). Direito das águas. O regime jurídico da Água Doce no Direito Internacional e no Direito Brasileiro. São Paulo: Atlas. 401p. 
Boff, L. (2015). Sustentabilidade: o que é: o que não é. (7ª ed.). Vozes, 200p.

Brasil. (1988). Constituição da República Federativa do Brasil de 1988. Brasília.

Brasil. (1997). Lei ${ }^{\circ}$ 9.433, de 8 de janeiro de 1997. Institui a Política Nacional de Recursos Hídricos, cria o Sistema Nacional de Gerenciamento de Recursos Hídricos. Brasília.

Brasil. (2019). Ministério da Saúde. Agrotóxicos, causa e prevenção. Brasília.

Carli, A. A. (2013). A água e seus instrumentos de efetividade. Campinas: Millennium, 359p.

Carneiro, F. F., Pignati, W., Rigotto, R. M., Augusto, L. G. S., Rizollo, A., Muller, N. M., Alexandre, V. P., Friedrich, K., \& Mello, M. S. C. (2012). Um alerta sobre os impactos dos agrotóxicos na saúde. Dossiê ABRASCO, Rio de Janeiro, 628p.

Dupas, G. (2007). O mito do progresso: ou progresso como ideologia. São Paulo, UNESP, 73-89p.

Coldebella, A., Gentilini, A. L., Piana, A. P., Coldebella, P. F., Boscolo, R. B., \& Feiden, A. (2018). Effluents from Fish Farming Ponds: A View from the Perspective of Its Main Components. Sustainability, 10, 3. 10.3390/su10010003

IBGE (2010). Instituto Brasileiro de Geografia e Estatística. (2010). Censo Demográfico.

IBGE (2017). Instituto Brasileiro de Geografia e Estatística. Estimativas da população do Brasil.

INPE (2021). Instituto Nacional de Pesquisas Espaciais. Queimadas.

Koche, J. C. (2011). Fundamentos de Metodologia Científica: teoria da ciência e iniciação à pesquisa. Petrópolis. Rio de Janeiro. Vozes. 185p.

Marconi, M. A., \& Lakatos, E. M. (2004). Metodologia Científica. (4 ${ }^{\text {a }}$ Ed.): Atlas. 141p.

Netto, J. P., \& Braz, M. (2008). Economia política: uma introdução crítica. São Paulo: Cortez, 1-39p.

ONU (1984). Organização das Nações Unidas. Declaração sobre o direito de desenvolvimento. Nova York.

ONU (2010). Organização das Nações Unidas. Declaração da “ONU Água” para o Dia Mundial da Água - 2010.

ONU (2010). Organização das Nações Unidas. Resolução da Assembleia Geral da Resolução A/RES/64/292.

ONU (1992). Organização das Nações Unidas. Conferência das Nações Unidas Sobre o Meio Ambiente e Desenvolvimento. Rio de Janeiro.

Nagalli, A., \& Nemes, P. D. (2009). Estudo da Qualidade de Água de Corpo Receptor de Efluentes Líquidos Industriais e Domésticos. Rev. Acadêmica, Ciências. Agrárias. Ambientais, Curitiba, 7(2), 131-144, abr./jun.

Nege, K. K., Nadaleti, W. C., Bortolotti, S. L. V., Silva, R. F., Favaretto, A. P., \& Manzani, V. (2016). Incidência de cânceres e o uso de agrotóxicos na região oeste do Paraná. Revista Brasileira de Engenharia e Sustentabilidade. 2(2), 11-16.

Pereira. A. S., Shitsuka, D. M., Parreira, F. J., \& Shitsuka, R. (2018). Metodologia da Pesquisa Científica. $1^{\text {a }}$ Ed. Universidade Federal de Santa Maria UFSM, Rio Grande do Sul. 119p.

Reigota, M. (2004). Meio ambiente e representação social. São Paulo: Cortez, 88p.

Rossoni, R., A., \& Moraes. M., L. (2020). Agropecuária e Desmatamento na Amazônia Legal Brasileira: uma análise espacial entre 2007 e 2017. Geografia em Questão. 13(03). https://doi.org/10.48075/geoq.v13i3.23536

Schons, S. M. (2012). A questão ambiental e a condição da pobreza. R. Katál. Florianópolis, 15(1), 70-78p, jan./jun.

SNIS (2020). Sistema Nacional de Informação sobre Saneamento. Diagnóstico dos Serviços de Água e Esgotos (anos-base 2012 a 2018). Brasília, 2020: Ministério das Cidades.

SNM (2021). Sistema Nacional de Meteorologia. Nota Conjunta - INMET/INPE/ CENSIPAM, 27 maio de 2021.

Volpato, G. (2019). Ciência da Filosofia à Publicação. (7ª Ed.) Best Writing. Botucatu. 312p.

Volpato, G. (2007). Bases Teóricas para Redação Científica. Cultura Acadêmica. São Paulo. 125p. 